\title{
PROGRAMA DE EDUCAÇÃO PELO TRABALHO PARA A SAÚDE E FORMAÇÃO PARA O SUS: REFLEXÕES TEÓRICAS A PARTIR DA VIVÊNCIA COMO PRECEPTORA
}

\begin{abstract}
Patrícia Pilatti
Mestranda em Saúde Coletiva, Universidade do Extremo Sul Catarinense, pattipilla@yahoo.com.br

Janine Moreira

Doutora, Universidade de Córdoba - Espanha,

jmo@unesc.net

Fabiane Ferraz

Doutora, Universidade Federal de Santa Catarina, olaferraz@gmail.com
\end{abstract}

\section{RESUMO}

Muito se tem discutido atualmente sobre a qualificação das práticas profissionais na área da saúde, principalmente no que se refere à integralidade do cuidado e ao comprometimento com os princípios e as diretrizes do Sistema Único de Saúde (SUS), a fim de romper com a concepção biologicista e individual. Ao considerar os pontos citados anteriormente, a formação em saúde é um pilar importante no direcionamento das açóes profissionais, sendo que a integraçáo entre ensino e serviço passa a ser aliada nesse processo como um espaço enriquecedor, à medida que permite problematizar e repensar o modelo instituído, favorecendo a construção de práticas cuidadoras e humanizadas (CECCIM; FERLA, 2009). Nesse contexto, insere-se a proposta do Programa de Educação 
pelo Trabalho para Saúde (PET-Saúde), que tem o objetivo de proporcionar aos estudantes de graduação a vivência junto com SUS e com comunidade, experienciando a realidade social e as práticas interdisciplinares. $\mathrm{O}$ objetivo deste estudo foi refletir, a partir do construto teórico de autores da Saúde Coletiva e da educação, sobre uma vivência como preceptora do Programa de Extensão PET Saúde/ Redes II - Urgência e Emergência, de uma cidade do sul do Brasil, a relação entre ensino e trabalho, seus conceitos e suas implicaçóes. As atividades de preceptoria se caracterizam por acompanhar e orientar os estudantes dos cursos envolvidos nos espaços de prática a se envolverem na universidade, em encontros mensais e em demais atividades que possam contribuir para a formação dos estudantes. Contudo, ainda não existe um movimento de trazer para a universidade ou inserir a discussão sobre formação do estudante junto com comunidade. Durante a vivência como preceptoras, percebemos que os estudantes tiveram a oportunidade de conhecer os serviços, os fluxos e o funcionamento e, à medida que foram se aproximando do trabalho realizado pelas equipes com os usuários, muitas dúvidas e questionamentos surgiram, sobre os quais tivemos a oportunidade de refletir e contribuir para uma formação mais crítica e questionadora, em relação ao sistema de saúde, seus princípios e suas práticas efetivas. Esse contato permitiu que os estudantes passassem a ter um olhar mais abrangente do SUS e de seus avanços, apesar das dificuldades ainda existentes. A partir dos relatos dos estudantes que estavam inseridos em campos de vivências mais "duros", como a Emergência Clínica do hospital, percebemos que muitas práticas ainda estão cristalizadas em um modelo biomédico. Neste caso, temos os dois lados: o estudante pode achar que isso é o suficiente, caso o preceptor e o tutor não o instiguem para uma formação crítica e de construção e reconstrução das práticas de saúde, ou o estudante pode perceber, refletir e até propor alternativas relacionadas às práticas de humanização do cuidado e tecnologias mais "leves", aspectos mobilizados na experiência aqui descrita. Todavia, para efetivar mudanças nas práticas, sabemos que há desafios relacionados à aceitação dos trabalhadores e gestores e, até mesmo, dos usuários. Nessa situação, muitas vezes, ficam difíceis a inserção e o aceite do estudante no serviço. Também, observamos que os tutores da universidade, às vezes, acabam por querer consolidar as práticas com saberes acadêmicos, desconsiderando o 